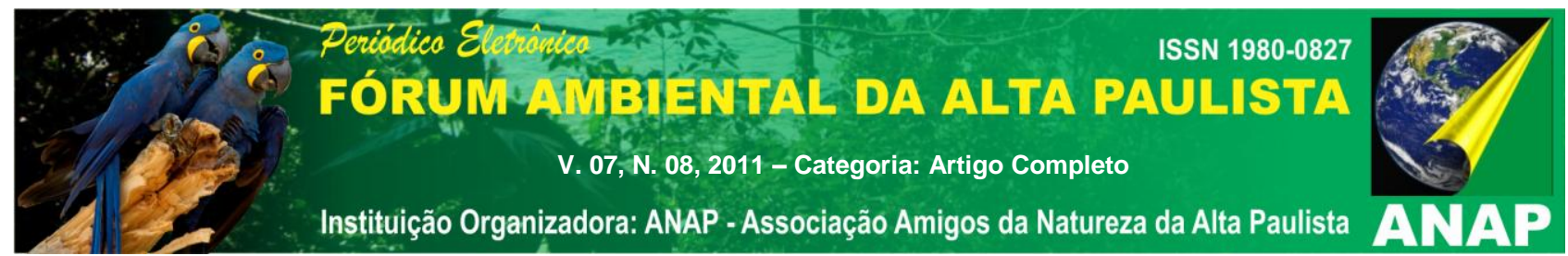

\title{
DESASTRES AMBIENTAIS EM JARAGUÁ DO SUL - SC: PERCEPÇÃO POPULACIONAL
}

\author{
Felipe Amaro da Silva ${ }^{1}$ \\ André Luiz Pinto ${ }^{2}$ \\ Agnes Cassia Dias ${ }^{3}$
}

Resumo: O Município de Jaraguá do Sul vem sofrendo ao longo dos anos pelos constantes desastres ambientais, nesse estudo priorizaram-se os casos dos anos de 2008 e 2011. Para entender o processo traumático de um desastre buscou-se enfatizar a percepção da população de Jaraguá do Sul frente aos desastres, foram levantados dados com base na percepção e interpretação após um desastre ambiental, e suas diferentes percepções sobre o desastre. Após entendermos a percepção de uma população traumatizada, podemos compreender ao fundo o que é um desastre, juntamente com as teorias estudadas ao longo do tempo sobre essa questão, a percepção vem agregar valores a ciência exata e teórica. $\mathrm{O}$ Município localiza-se, em um vale da Serra do Mar que apresenta vulnerabilidade a processos naturais de desnudação que, dadas as condições climáticas, geológicas, geomorfológicas e de ocupação antrópica aumentam o risco de ocorrências de desastres naturais como inundações e movimentos de massa. $O$ município de Jaraguá do Sul declarou situação de emergência em 20 de novembro de 2008 e, posteriormente, estada de calamidade pública, em 14 de dezembro do mesmo ano. Já no ano de 2011, precisamente no mês de janeiro e fevereiro o município entrou em estado de alerta, com riscos de enchentes e deslizamentos.

Palavras chave: Jaraguá do Sul; Percepção Ambiental; Valoração Ambiental; Percepção de Risco Desastres Ambiental; Evento Climático Extremo.

\footnotetext{
1 Geógrafo pela Universidade Federal de Mato Grosso do Sul - UFMS campus de Três Lagoas Título de Bacharel em Geografia. Av. Ranulpho Leal 3484 - Três Lagoas - MS. CEP 79610-100.Endereço Eletrônico: felipeamaro25@hotmail.com.

2 Professor Doutor, Docente da Universidade Federal de Mato Grosso do Sul - UFMS campus de Três Lagoas Título de Doutor. Av. Ranulpho Leal 3484 - Três Lagoas - MS. CEP 79610-100.Endereço Eletrônico: andreluiz@ceul.ufms.br

${ }^{3}$ Geógrafa pela Universidade Federal de Mato Grosso do Sul - UFMS campus de Três Lagoas Título de Bacharel em Geografia. Av. Ranulpho Leal 3484 - Três Lagoas - MS. CEP 79610-100. Endereço Eletrônico: agnescdias@gmail.com
} 


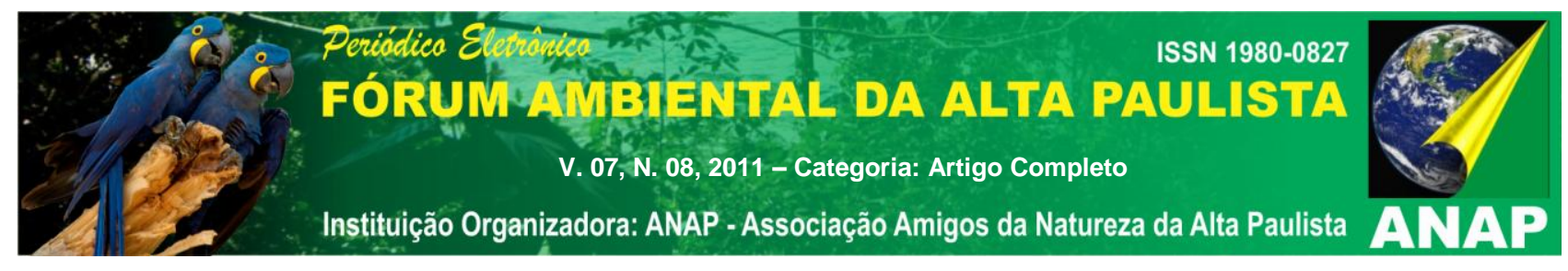

\section{INTRODUÇÃO}

O Município de Jaraguá do Sul situa-se entre latitude de $26^{\circ} 29^{\prime} 10^{\prime \prime S}$ e à longitude de 4904'00'W (Figura 1). Faz divisa com Campo Alegre, São Bento do Sul ao norte; Blumenau, Massaranduba, Pomerode e Rio dos Cedros ao sul; Guaramirim, Joinville e Schroeder a leste, e com Corupá a oeste. Estando ao norte do Estado de Santa Catarina, no Vale do Itajaí, ou, turisticamente, conhecido como Vale Europeu, é o terceiro pólo industrial do Estado e tem população de 129.970 habitantes (IBGE, 2007). 

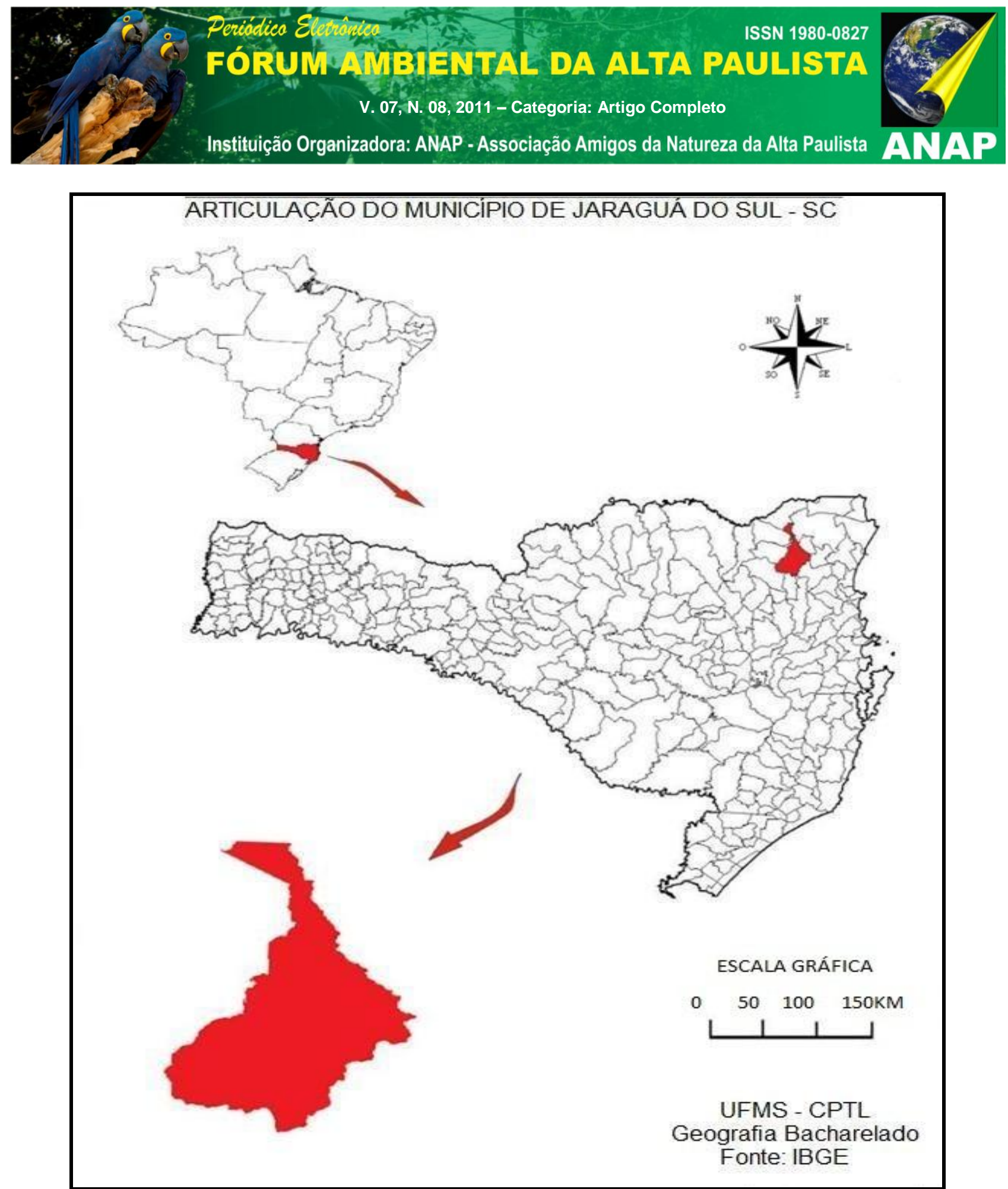

Figura 1: Articulação do Município de Jaraguá do Sul - SC Reeditoração e Org.: AMARO, F.S (2010).

A área de estudo foi escolhida por localizar-se, em um vale da Serra do Mar que apresenta vulnerabilidade a processos naturais de desnudação que, dadas as condições climáticas, geológicas, geomorfológicas e de ocupação antrópica aumentam o risco de ocorrências de desastres naturais como inundações e movimentos de massa.

O evento climático extremo no último trimestre de 2008 em Santa Catarina proporcionou uma elevada precipitação, e devido à sua concentração e continuidade 


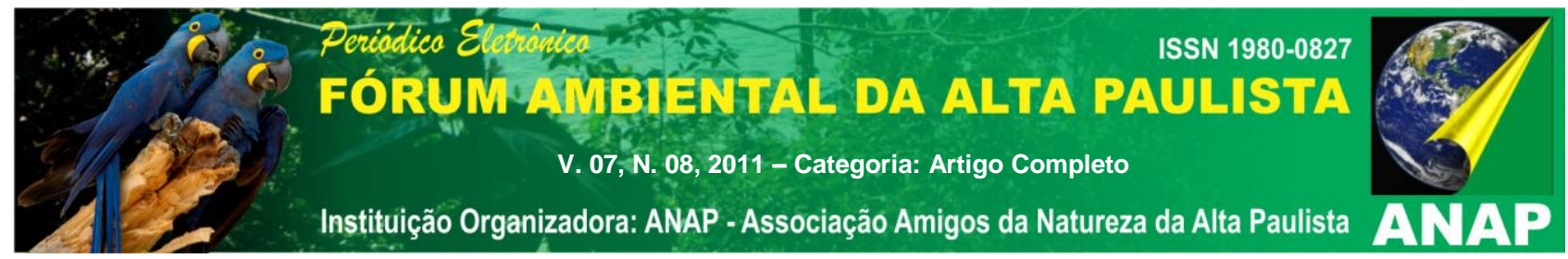

provocou enchentes em áreas de declividade e movimentação de massa nas encostas. Segundo Silva Dias (2009), entre 20 e 24 de novembro ocorreu a maior precipitação do Estado, $202 \mathrm{~mm}$. Desmatamentos, ocupações irregulares em encostas de montanhas, habitações à beira de rios, rodovias mal planejadas, um solo morfologicamente frágil somados às chuvas concentradas, contribuíram diretamente a essa catástrofe; entre os anos de 2000 e 2005 no Estado de Santa Catarina desmatou-se uma área equivalente à cidade de Florianópolis e boa parte ocorreu em encostas e morros (REVISTA ÉPOCA, 2008).

Em janeiro de 2011, o município de Jaraguá do Sul, em um curto período de tempo, voltou a ser atingida com uma grande quantidade de precipitação, novamente a vulnerabilidade já característica do município aliado a esse evento, trouxe uma nova catástrofe a sua população, menor que a de 2008, porém com danos ao município e a sua população.

Ao compreender a percepção e a interpretação da paisagem sob perspectivas psicossociais, devem-se considerar as diferentes realidades culturais responsáveis pela construção/desconstrução das paisagens, assim como pela manutenção dos processos conservacionistas e preservacionistas. Pois a cultura abrange conjuntos de regras interiorizadas, nas quais se destacam saberes e práticas de um determinado grupo, delineando um modo de ser e de vive e, conseqüentemente, de relacionar-se com e desenvolver leituras sobre a paisagem (GEERTZ, 1978).

A percepção envolve aspectos culturais, onde estímulos de reação e a cognição constituem os valores dos elementos culturais, portanto o observador apreende mais detalhadamente objetos familiares, que remetem a significados dentro de seu repertório sócio-cultural. Desta forma, a cultura resulta de diferentes formas de percepção, isto é, a peculiaridade da percepção individual sobre o mundo, que decorre de uma seleção e ordenação dos elementos apreendidos. Neste ponto, pode-se considerar a correlação entre a percepção ambiental e a fenomenologia, que, por sua vez, tem como base a essência que os objetos apresentam para os indivíduos, assim como a experiência de vida. 


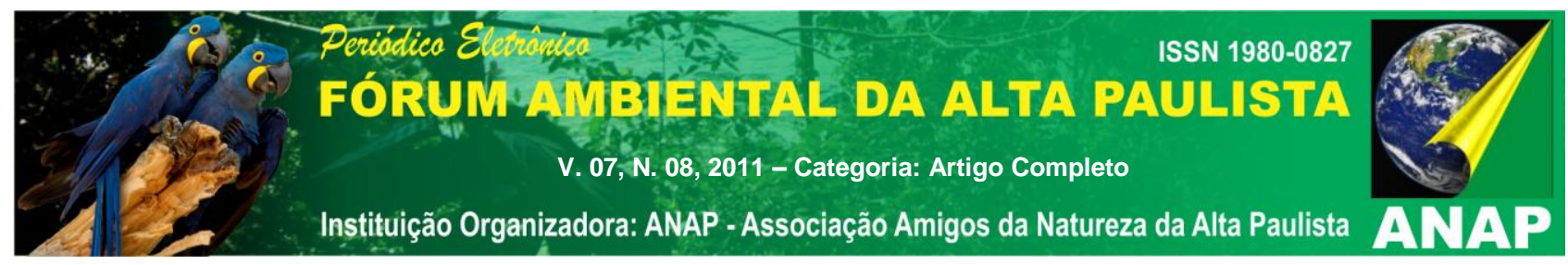

\section{OBJETIVO}

O objetivo do presente trabalho foi o a discussão e análise dos desastres de 2008 e 2011 e avaliar a percepção da população de Jaraguá do Sul frente aos desastres ocorridos nesses dois períodos, tabulando as respostas dos questionários que foram respondidos voluntariamente pela população das áreas atingidas, que somados com os dados da Defesa Civil Municipal e Estadual, facilitaram a análise da percepção populacional como um todo no municio.

\section{METODOLOGIA}

Para a fase inicial do trabalho, foi realizado o levantamento bibliográfico relevante sobre desastres naturais, antrópicos, eventos climáticos extremos, e também sobre as teorias da percepção, interpretação e valoração ambiental, foram levantados dados climáticos, históricos, topográficos, geomorfológicos, e hidrológicos dos desastres de 2008 e 2011 nos órgãos públicos municipais e pesquisas na mídia, como revistas, jornais, notícias online, etc. Foram aplicados 100 (cem) questionários nas 5 (cinco) áreas mais atingidas do município, segundo dados da defesa civil municipal, logo após foi realizada a tabulação dos dados dos questionários e comparados com os dados obtidos dos órgãos públicos e notícias veiculadas pela mídia. O método de amostragem foi aleatório, de acordo com disponibilidade da população em transito, nas praças centrais desses bairros, que voluntariamente responderam ao questionário.

\section{RESULTADOS}

Para a análise da percepção e da interpretação da população de Jaraguá do Sul sobre os desastres ambientais, foram condicionados questionários de campo, baseados em BERTOLI (2006), que propiciou a base para a elaboração e interpretação do questionário, estes foram testados e ajustados em fevereiro de 2011 (Tabela 1). 
Tabela 1: Áreas de Jaraguá do Sul - SC, escolhidas para a aplicação do questionário, população estimada de cada área/bairro de Jaraguá do Sul - SC, escolhidas para a aplicação do questionário, população estimada de cada área/bairro.

\begin{tabular}{|c|c|c|}
\hline Área 1 & População estimada & N. Questionários \\
\hline Centro & 19.000 & \\
\hline Vila Nova & 6.000 & 20 \\
\hline Nova Brasília & 8.000 & \\
\hline \multicolumn{3}{|l|}{ Área 2} \\
\hline Tiffa Martins & 5.000 & \\
\hline Vila Lenzi & 7.000 & 20 \\
\hline Jaraguá esquerdo & 9.000 & \\
\hline \multicolumn{3}{|l|}{ Área 3} \\
\hline Nereu Ramos & 4.000 & \\
\hline Santo Antônio & 3.000 & \\
\hline Três rios do norte & 3.500 & 20 \\
\hline Três rios do sul & 4.000 & \\
\hline \multicolumn{3}{|l|}{ Área 4} \\
\hline Vila lalau & 8.000 & \\
\hline Centenário & 7.000 & 20 \\
\hline Ilha da figueira & 13.000 & \\
\hline \multicolumn{3}{|l|}{ Área 5} \\
\hline Rio da luz & 17.000 & \\
\hline São Luiz & 4.000 & \\
\hline Barra do rio cerro & 2.500 & 20 \\
\hline Barra do rio molha & 2.000 & \\
\hline Total & 122.000 & 100 \\
\hline
\end{tabular}

O questionário relevou que $42 \%$ dos entrevistados foram atingidos por algum tipo de desastre ambiental no ano de 2008 , e $58 \%$ em 2011, o que mostra bem a 


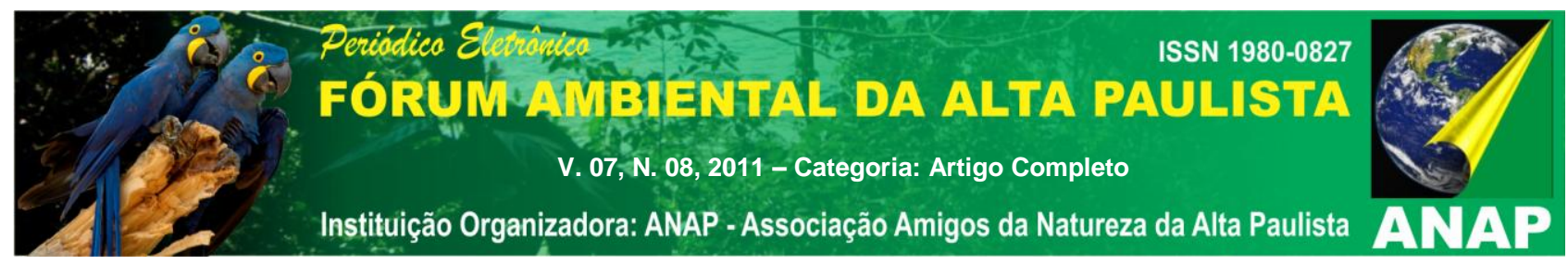

abrangência e magnitude das catástrofes no município. De acordo com a Defesa Civil Municipal $35 \%$ da população foram atingidas por algum tipo de desastre no ultimo trimestre de 2008 e $65 \%$ pelo desastre de janeiro de 2011 , como mostrado no gráfico 1 , o que dá credibilidade a pesquisa, pois o questionário aplicado não fugiu das proporções, mensurada pelos dados da defesa civil municipal.

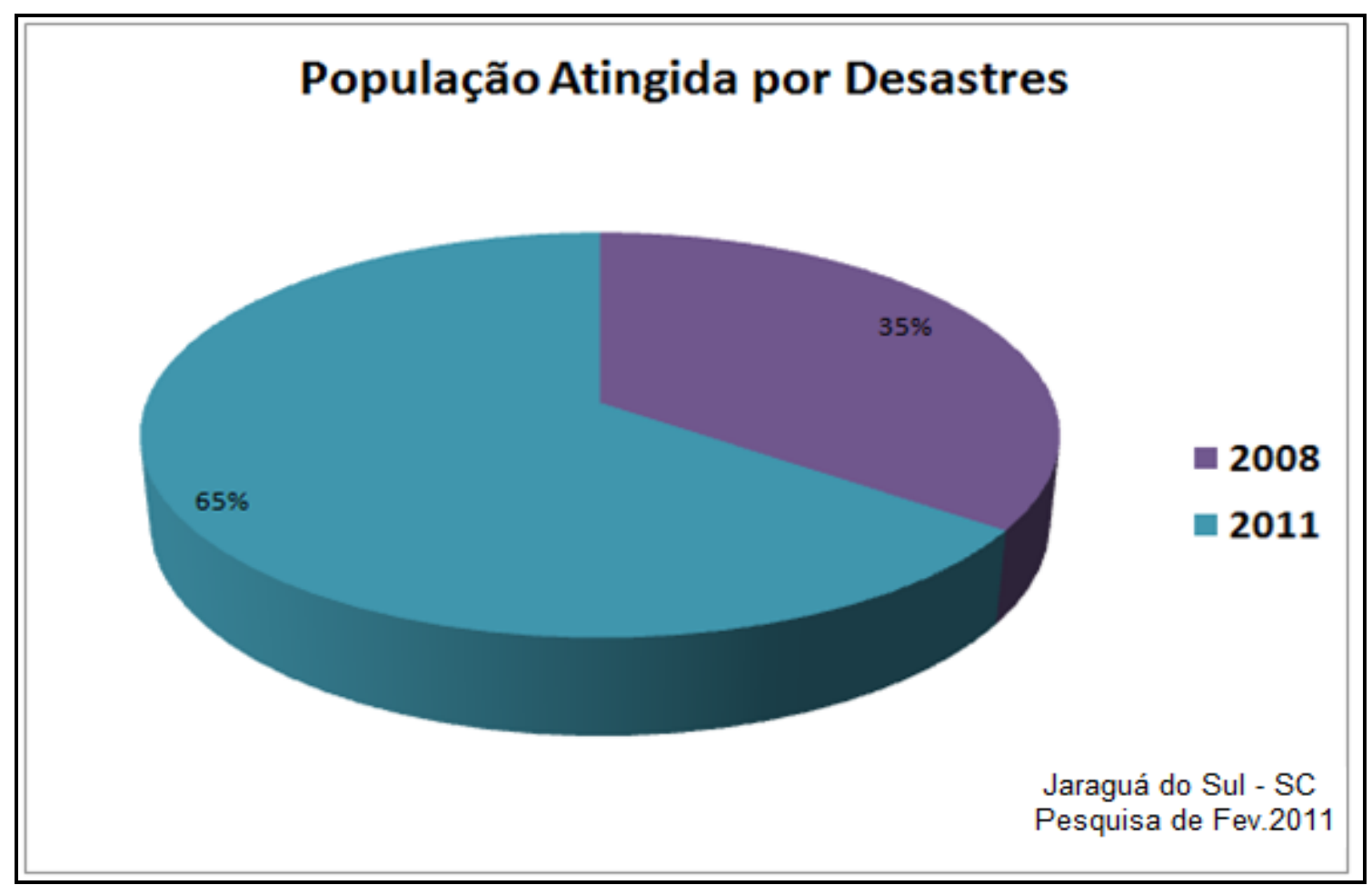

Gráfico 1: Porcentagem da população atingida por algum tipo de desastre, 2008/2011.

Fonte: Defesa Civil de Jaraguá do Sul-SC

Reeditoração e Org.: AMARO, F.S 2010.

A principal causa dos deslizamentos, segundo $63 \%$ dos entrevistados, é a chuva, a grande responsável pelo processo, $28 \%$ dos entrevistados acha que a causa é natural e agravada pelas ações antrópicas de desmatamento e os cortes/aterros e 9\% não quiseram ou não souberam responder.

Pela percepção do entrevistado $83 \%$ não consideram morar em uma área de risco, mesmo tendo sofrido algum tipo de impacto dos desastres ao longo dos anos. Burton et. al. (1978) salienta que as pessoas têm uma capacidade de aprender a viver com eventos de perigo e, contanto que o impacto não seja grande, elas podem preferir viver com isto, em vez de agir em relação ao problema. 


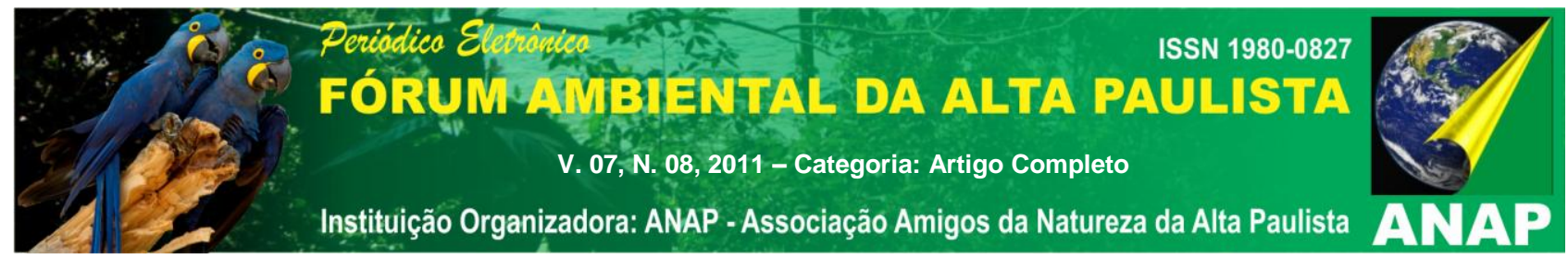

Para LYNCH (1997), a imagem mental dos cidadãos, impregnada a partir de aspectos visuais dos núcleos urbanos, é de suma importância para o reconhecimento e organização das partes da cidade (legibilidade), de forma coerente (referências), permitindo sensações de segurança e resultando no conforto e rapidez de deslocamentos. Como atributo fundamental da paisagem urbana ressalta a necessidade do estabelecimento de identidade, determinada por características próprias e/ou exclusivas; de estrutura, formada pela relação espacial e formal entre observador e objeto; e de significado, definido em um sentido prático ou afetivo.

Em Jaraguá do Sul, é comum ver casas luxuosas construídas em íngreme montanha, com seus alicerces "firmes" e "seguros", de acordo com quem mora, o querer e o prazer dessas pessoas em morarem em um lugar alto, com uma vista panorâmica da cidade e paisagem em torno, muitas vezes faz com que não se leve em conta o risco do lugar, principalmente se esse for um local de alta vulnerabilidade, como o topo de um morro ou uma encosta muito íngreme.

Apesar do conhecimento do risco de deslizamento por aqueles que moram a mais tempo nessas áreas consideradas vulneráveis, pouco se tem feito para reduzi-lo, priorizando-se medidas sempre individuais e estruturais como a construção de muro de arrimo.

Para os moradores indagados sobre as enchentes e os alagamentos cerca 43 $\%$, afirmam que uma maneira para se evitar esses impactos é construir suas casas sobre um aterro mais alto que o nível da rua. Ações de caráter coletivo como o controle das construções, a preservação ou reposição da vegetação, bem como a canalização das águas, são soluções citadas pelos moradores, porém, geralmente não colocadas em prática. Embora revegetar seja uma das prioridades, pode-se constatar que alguns moradores retiram a vegetação, como sinônimo de limpeza ou para implantar novas edificações.

Dessa forma, as pessoas estão dispostas a pagar algum valor monetário pelo fato de reconhecerem a função física, social e de existência dos recursos ambientais paisagísticos. Visto que a construção em encostas é muito mais onerosa do que nas regiões mais planas, contudo a vista e a interação com a natureza plena, bem como os 


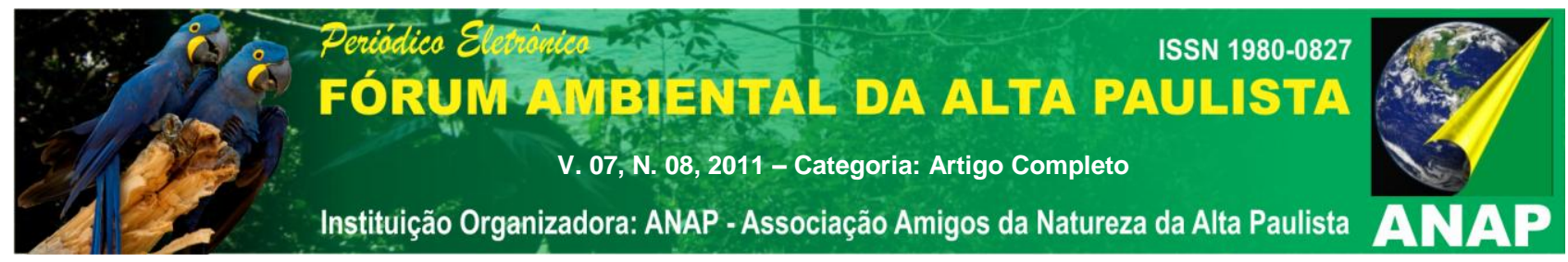

riscos ambientais de eventos perigosos são maiores quanto maiores às declividades e usos da terra degradantes dos terrenos.

Frente à ocorrência de um deslizamento na área alguns entrevistados não sabiam qual a melhor atitude a ser tomada, demonstrando falta de definição quanto às ações e um baixo grau de organização local em relação aos desastres. Para a maior parte dos entrevistados, as ações se reduzem à saída da casa durante o evento, contato com a Defesa Civil e posterior limpeza do terreno.

Em comparação os anos de 2008 e 2011, podemos notar com base no questionário aplicado, que o município sofreu muito mais com enchentes do que com movimentações de massa, principalmente em 2011, comparando com 2008, nesse ano 25\% dos entrevistados sofreram com enchentes, já no ano de 2011 , esse percentual foi de $55 \%$ ou seja, um aumento de $30 \%$ da população atingida por enchentes. Já sobre os deslizamentos e desmoronamentos houve uma diminuição em 2011 com relação a 2008 que atingiu 16\% dos entrevistados e em 2011 atingiu 11\% dos entrevistados como mostra o gráfico 2.

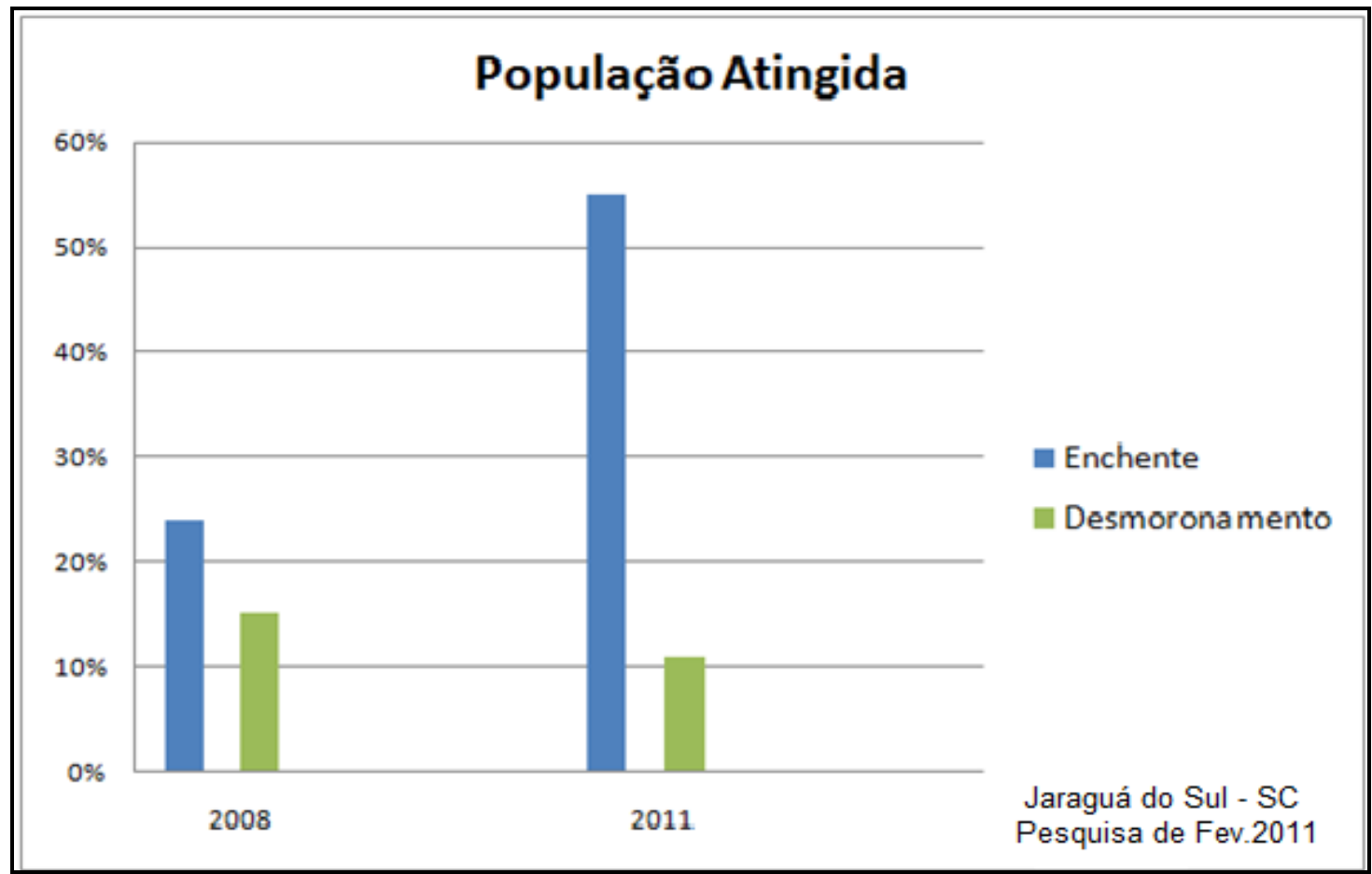

Gráfico 2: Comparativo dos anos 2008 e 2011 com relação a população atingida por enchente e desmoronamento.

Reeditoração e Org.: AMARO, F.S (2010). 


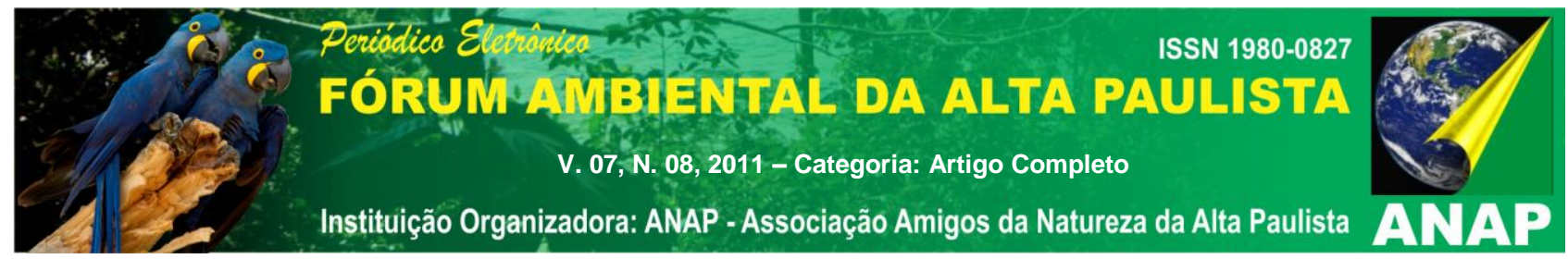

A absorção do perigo é definida pela capacidade que cada comunidade tem de permanecer inalterada no acontecimento de um desastre, sendo capaz de absorver o impacto, durante as entrevistas realizadas no município de Jaraguá do Sul, foi questionado se as pessoas continuariam morando no lugar após os deslizamentos de terra, enchentes e alagamentos $64 \%$ respondeu que sim, especialmente se a casa não fosse atingida. Perguntou-se também para aqueles que já foram vítimas desses tipos de desastres se eles continuariam morando naquele lugar após a incidência de outro evento. A grande maioria respondeu positivamente.

Dos entrevistados $83 \%$ não têm condições financeiras de se realocarem em um local não considerado de "risco", e afirmam que o poder público não agiu para mitigar os riscos de um novo desastre, de acordo com $78 \%$ dos entrevistados não houve mudança na parte do poder público em seus bairros após a catástrofe de 2008 , e $84 \%$ não vem perspectiva de mudança após o recente desastre de 2011.

Frente às questões ambientais, os entrevistados se mostraram favoráveis a educação ambiental, 92\% acreditam que com uma educação ambiental, frente às percepções ambientais sobre se instalar em áreas de risco, sobre poluição dos rios, e vias públicas, galerias pluviais, etc. iriam conscientizar a população jaraguaense sobre a vulnerabilidade do município e atuaria como prevenção frente a um possível novo desastre.

As formas individuais e coletivas dos moradores em relação aos riscos variam de acordo com valores individuais. Para Burton et. al. (1978) as pessoas com mais experiências com desastres e que tiveram uma relação de perda econômica tendem a perceber os riscos como problemas ambientais, salientando, entretanto, que a possibilidade de negação de uma ameaça é maior quanto mais próximo os moradores estiverem dela.

Outros fatores que influenciam na percepção, conforme Burton et. al. (1978), é a freqüência e duração do desastre; assim os deslizamentos, por serem rápidos e muitas vezes não ocorrem, nos mesmos locais, parece não fazer parte do cotidiano. A tolerância dos moradores é bastante grande, especialmente daqueles que com muita luta conseguiram construir o pouco que possuem. 


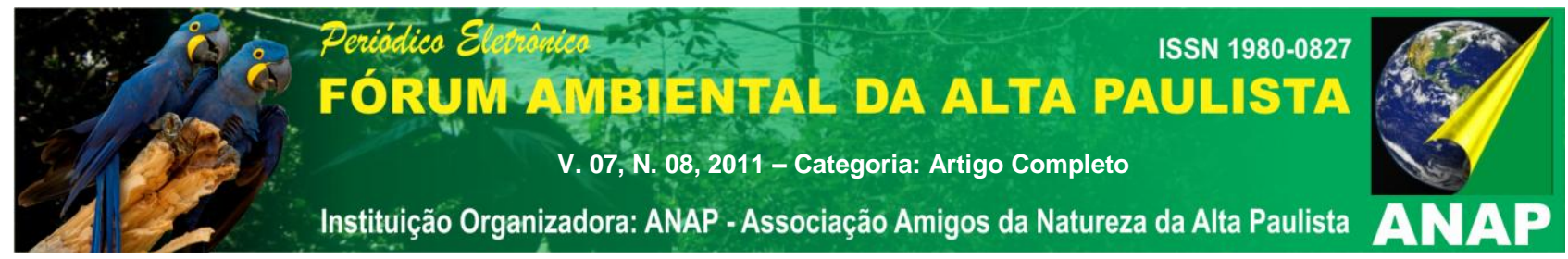

Nesse sentido, a valoração do meio ambiente constitui-se em um conjunto de métodos e técnicas que têm por finalidade estimar os valores para os atributos ambientais, que por sua própria natureza, são considerados como "bens públicos", portanto, disponíveis para todos. (SANTOS e MORET, 2009). As belezas cênicas de Jaraguá do Sul constituem patrimônio natural, que deva ser valorado, devido sua importância histórica, cultural e ambiental que possui para a população local, que as vê como belo e não como risco a sua própria sobre vivencia.

\section{Percepção, Interpretação e Valoração dos Desastres Ambientais Climáticos.}

A consciência dos problemas ambientais aparece como um ponto importante a respeito do crescimento material e econômico e da qualidade de vida. A qualidade de vida para alguns é obtida pela limitação das produções materiais e para outros, ao contrário, ela é proporcional à abundância dos produtos.

O meio ambiente é valorado quando alguém se dispõe a pagar determinada tarifa para ter acesso a áreas de desfrute e lazer ecológico. A qualidade ambiental está embutida no valor adicional do preço de um imóvel que proporcione ao comprador maior sensação de bem-estar pelo usufruto de certa amenidade ambiental existente em sua localização. Valora-se o meio ambiente quando determinada atividade econômica modificadora da paisagem é preterida em favor da manutenção de suas características naturais. E torna-se ainda mais necessária quando surgem demandas específicas como arbítrio do valor de multa por infração ambiental ou fixação de montante necessário à compensação por dano causado ao meio ambiente em transações judiciais (MUNHOZ, 1989).

A valoração ambiental é matéria nova e envolve conceitos que tendem a mensurar para resguardar o equilíbrio ecológico e os recursos ambientais, tendo como referência o Desenvolvimento social e econômico, ainda não muito relacionado com o Sustentável. Algumas reflexões merecem ser realizadas, iniciando pelos próprios métodos empregados e as críticas a eles endereçadas. Jacobs (1995) faz um balanço de críticas à abordagem neoclássica que embasa os métodos de valoração. 


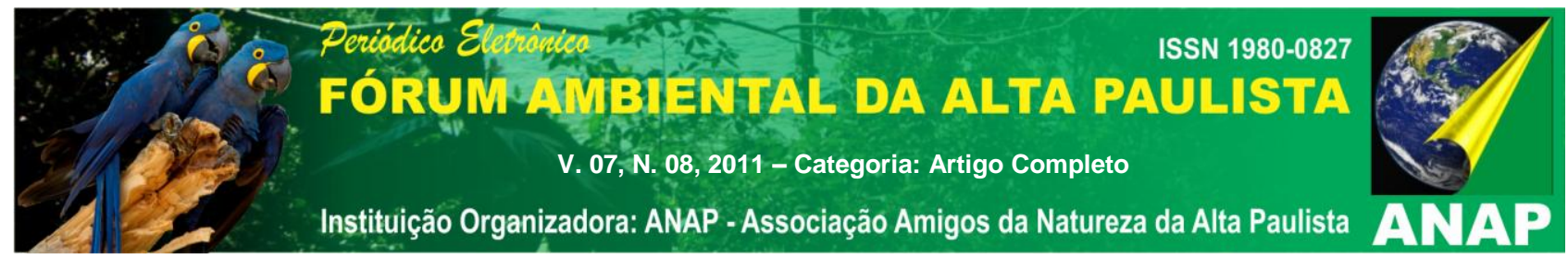

A percepção é a captação, seleção e organização das informações ambientais, orientada para a tomada de decisão que torna possível uma ação inteligente e que se expressa por ela. A percepção do ambiente permite atuar. Adquire-se ao mesmo tempo em que se atua e modifica-se em função dos resultados da atuação. Ou seja, a percepção do meio ambiente é aprendida e está carregada de afetos que traduzem juízos acerca dele. Estão juntos o cognitivo e o emocional, o interpretativo e o avaliativo. Portanto a percepção ambiental é aprendida e aparece nos juízos que formamos sobre o meio ambiente e nas intenções modificadoras que empregamos. É resultante tanto do impacto objetivo das condições reais sobre os indivíduos quanto da maneira como sua interveniência social e valores culturais agem na vivência dos mesmos impactos.

Entretanto risco é um aspecto da percepção da qualidade ambiental. São os fatores de risco que influenciam as pessoas a se darem conta de sua existência e ser consciente da vulnerabilidade, o que vai determinar a noção de cuidado/cautela. O risco em si não se constitui num desastre, mas sim um fator que propicia a iminência de um desastre. Por exemplo, a região sul do Brasil, é considerada uma área de risco devido à possibilidade de se formarem ciclones extratropicais (perturbações comuns de ocorrerem no oceânico atlântico, próximos a costa catarinense, podendo causar ressacas, chuvas e ventos fortes). Entretanto o fator risco pode ser maior ou menor de acordo com o tipo de ocupação territorial da população, ou seja, morar em encostas em condições anormais como as favelas tornam o risco mais contundente, constituindo-se o ciclone num alto fator de risco para aquela população. De igual forma e mais comum, as chuvas com elevado índice pluviométricas elevam a possibilidade de deslizamento de terra e pedras. $O$ número de perdas humanas e materiais são maiores em regiões de concentração de população miserável.

\section{CONSIDERAÇÕES FINAIS}

Os resultados do presente estudo demonstram que os desastres ambientais climáticos que atingiram Jaraguá do Sul - SC teve impactos diretos sobre a população. No entanto, os resultados demonstram que, em função de uma separação sócio-econômica 


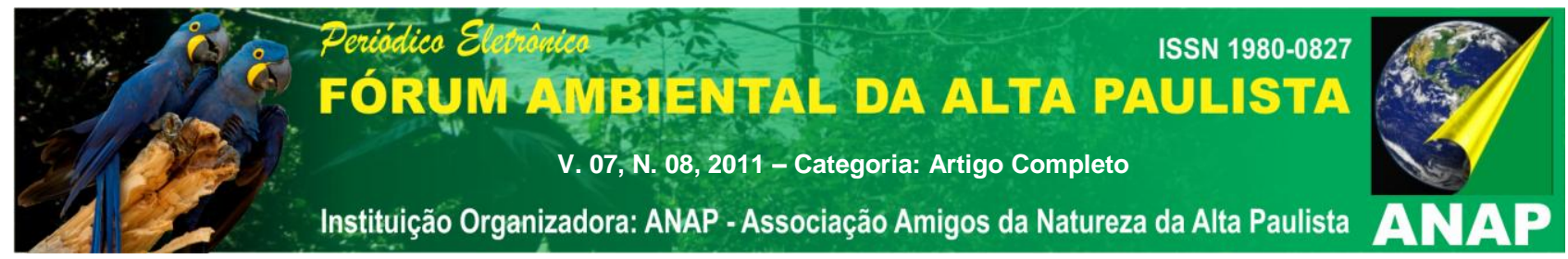

existente em seus habitantes, a percepção acerca de suas causas e impactos não foi tão homogênea quanto se esperaria em função da dimensão catastrófica que o evento teve sobre o cotidiano de toda a área urbana.

O município como um todo sofreu com a forte concentração de precipitação na região do Vale do Itajaí, com grandes perdas tanto materiais como humanas, servindo de alerta a toda população e principalmente as autoridades, para que se possam criar medidas de prevenção, para que no futuro o município possa estar preparado e melhor equipado para lidar com esse tipo de evento.

Políticas de remanejamento de famílias que estão em áreas consideradas de risco, de conscientização dessa população sobre os perigos de se morar nessas áreas, aliada à educação ambiental, e de saneamento básico, principalmente na destinação correta dos resíduos sólidos para evitar a obstrução das águas pluviais, são algumas maneiras de se tentar a diminuição de uma possível nova catástrofe no município; juntamente com políticas públicas preocupadas em não impermeabilizar toda área urbana a fim de mitigar os efeitos dos eventos climáticos extremos que possam surgir.

Com base na análise dos questionários, na interpretação e tabulação dos dados, juntamente com todo o levantamento bibliográfico e webgráfico feito, e possível constatar que a população de Jaraguá do Sul - SC não está preparada psicologicamente para um novo desastre. E o município também não está preparado para suportar um novo evento climático extremo, pois os órgãos públicos parecem não se interessar em mitigar os efeitos de um possível novo desastre e muito menos de trabalhar juntamente com a comunidade para prevenir e preparar o município para novos desastres, para que possa no mínino ser reduzido o risco da vida humana.

\section{REFERENCIAS}

BBC Brasil. Brasil é o país das Américas mais afetado por desastres.

2003.<http://www.bbc.co.uk/portuguese/no.html > Acesso em: 05 de maio de 2008.

BERQUE, A. Paisagem-marca, paisagem-matriz: elementos da problemática para uma geografia cultural. In: CORRÊA, R. L.; ROSENDAHL, Z. (Org.). Paisagem, tempo e cultura. Rio de Janeiro: EdUERJ, 1998. p. 84-97. 


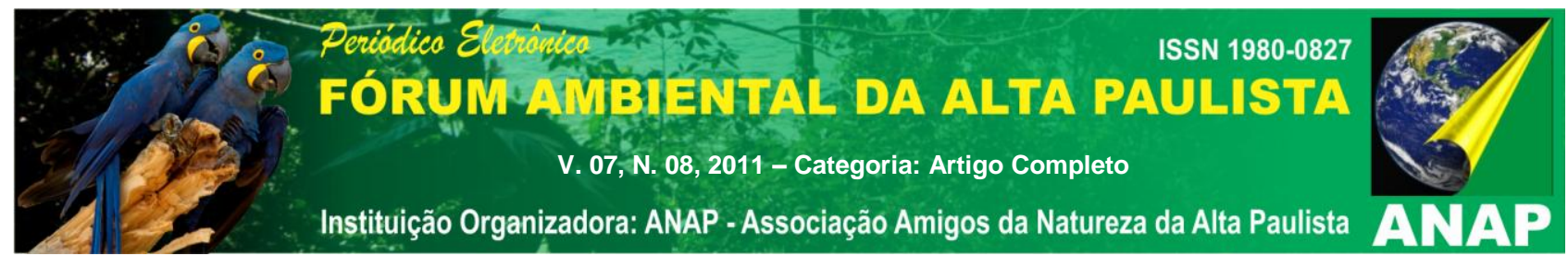

BERTOLI, Daiane. Dinâmica da Sub-Bacia do Ribeirão Chico de Paulo (Jaraguá do Sul- SC): Urbanização e Conflitos Decorrentes. Dissertação de Mestrado. Universidade Federal de Santa Catarina (UFSC), Florianópolis, 2006.

BURTON, I; KATES, R.W.; WHITE, G.F. The Environment as Hazard. New York: Oxford University Press, 1978.

Como evitar as enchentes e seus danos. Época. Rio de Janeiro. 22 dez. 2008 http://revistaepoca.globo.com/Revista/Epoca/0, EMI20108-15223,00.html. Acessado em 15/04/2010.

DEFESA CIVIL. Alerta para deslizamentos e alagamentos, 12 nov. 2008.

http://www.defesacivil.sc.gov.br/index.php?option=com content\&task=view\&id=486\&ltemi $\underline{\mathrm{d}=262}$ Acessado em 24/03/2010

EMÍDIO, T. Meio ambiente \& paisagem. São Paulo: SENAC - São Paulo, 2006.

GEERTZ, C. A interpretação das Culturas. Rio de Janeiro, Zahar, 1978.

JACOBS, M. Economia verde: medio ambiente y desarrollo sostenible: estratégias baseadas em incentivos: impostos e subsídios e as emissões. Colombia: Tm Editores e Ediciones Uniandes, 1995. 327-342.

LYNCH, K. A imagem da cidade. Trad. de Jefferson Luiz Camargo. São Paulo: Martins Fontes, 2006.

MUNHOZ, D. G. Economia aplicada: técnicas de pesquisa e análise econômica. Brasília: Editora UNB, 1989.

OLAM, Ciência e Tecnologia, Rio Claro - SP, 2009.

SANTA CATARINA. Defesa Civil do Estado de Santa Catarina, "Dados dos acontecimentos em Jaraguá do Sul a partir de novembro de 2008". Arquivo em Word cedido pela Defesa Civil Municipal de Jaraguá do Sul 22 jan 2010. S/D

SANTOS, F. B. N; MORET, A. S. Valoração Ambiental e Sustentabilidade.

SILVA DIAS, A. F. (Ed.) As chuvas de novembro de 2008 em Santa Catarina: um estudo de caso visando à melhoria do monitoramento e da previsão de eventos extremos. Nota Técnica do Centro de Previsão do Tempo e Estudos Climáticos do Instituto Nacional de Pesquisas Espaciais, sobre os acontecimentos catastróficos de 2008 no estado de Santa Catarina. São José dos Campos - SP, 2009. 